\title{
PEMODELAN STRUKTUR BANGUNAN DI MAMUJU PASCA GEMPABUMI 15 JANUARI 2021
}

\section{MODELING OF BUILDING STRUCTURES IN MAMUJU AFTER THE JANUARY $15^{\text {th }} 2021$ EARTHQUAKE}

\author{
Mulyo Harris Pradono', Shafira Rahmadilla Hape ${ }^{1}$, Ahmad Fauzi Yunus ${ }^{1}$, dan Muhammad Ravi \\ Yuvhendmindo ${ }^{1}$ \\ ${ }^{1}$ Pusat Teknologi Reduksi Risiko Bencana, Kedeputian Bidang Teknologi Pengembangan Sumberdaya \\ Alam, Badan Pengkajian dan Penerapan Teknologi, Gedung 820, Geostech, Kawasan PUSPIPTEK, \\ Serpong, Tangerang 15314, telepon: (021) 75791378 \\ e-mail: mulyo.harris@bppt.go.id
}

\begin{abstract}
The Mamuju earthquake on January 15, 2021 damaged several buildings in Mamuju City. The epicenter is approximately $34 \mathrm{~km}$ from the city. According to BMKG, the intensity of the earthquake in Mamuju was VI MMI with a recorded peak acceleration of the earthquake vibration of $150 \mathrm{gal}\left(1.5 \mathrm{~m} / \mathrm{sec}^{2}\right)$. There was damage that led to the collapse of many buildings, so it was deemed necessary to conduct an assessment of the buildings in Mamuju. In this paper, modelings are carried out for the surveyed buildings that represent moderate damaged and minor damaged buildings. Some of buildings were built before year 2010, therefore the standard used for designing the building was SNI 1726 2002. In this SNI, Mamuju City is still in the low earthquake zone category. In the SNI 2012 and 2019 standards, the Mamuju city is in higher earthquake hazard. The modeling of buildings built that refered to 2002 and 2019 standards needs to be carried out for better understanding and possible retrofitting.
\end{abstract}

Keywords: Mamuju earthquake, building structures, structural models, structural behavior

\begin{abstract}
ABSTRAK
Gempa Mamuju pada 15 Januari 2021 merusak beberapa bangunan di Kota Mamuju. Pusat gempa berjarak sekitar $34 \mathrm{~km}$ dari kota. Menurut BMKG, intensitas gempa di Mamuju adalah VI MMI dengan percepatan puncak getaran gempa tercatat 150 gal $(1,5 \mathrm{~m} / \mathrm{det} 2)$. Terjadi kerusakan yang mengakibatkan runtuhnya banyak bangunan, sehingga dipandang perlu untuk melakukan penilaian terhadap bangunan-bangunan di Mamuju. Dalam makalah ini, pemodelan dilakukan untuk bangunan yang disurvei yang mewakili bangunan rusak sedang dan rusak ringan. Beberapa bangunan dibangun sebelum tahun 2010, sehingga standar yang digunakan untuk merancang bangunan adalah SNI 1726 2002. Dalam SNI ini, Kota Mamuju masih dalam kategori zona gempa rendah. Dalam standar SNI 2012 dan 2019, kota Mamuju berada dalam bahaya gempa yang lebih tinggi. Pemodelan bangunan yang dibangun mengacu pada standar 2002 dan 2019 perlu dilakukan untuk pemahaman yang lebih baik dan kemungkinan perkuatan.
\end{abstract}

Kata kunci: Gempa Mamuju, struktur bangunan, model struktur, perilaku struktur 


\section{PENDAHULUAN}

\subsection{Latar Belakang}

Kejadian gempabumi 15 Januari 2021 pukul 02:28:21 WITA dini hari mengakibatkan kerusakan berat pada sebagian bangunan di Kabupaten Mamuju, Sulawesi Barat. Gempa ini berkekuatan $6.2 \mathrm{SR}$, dengan kedalaman 38 $\mathrm{km}$, dan lokasi 2.97 LS - 118.99 BT. Berdasarkan data per 17 Januari 2021 pukul 20.00 WIB, Badan Nasional Penanggulangan Bencana melaporkan jumlah korban meninggal dunia akibat gempa M6,2 di Provinsi Sulawesi Barat menjadi 81 orang, dengan rincian 70 orang meninggal dunia di Kabupaten Mamuju dan 11 orang di Kabupaten Majene (BNPB, 2021). Berdasarkan informasi dari BMKG, gempa ini dirasakan (MMI): V-VI Mamuju, IV-V Majene, III Palu, dan II Makasar.

Berdasarkan pemberitaan detik.com, sebelumnya gempa bumi juga pernah terjadi di wilayah Sulawesi Barat pada 11 April 1967 dengan kekuatan 6,3 SR, gempa ini mengakibatkan kerusakan pada sebagian bangunan di wilayah Mamuju dan Majene. Dua tahun setelahnya gempa bumi terjadi lagi pada 23 Februari 1969 dengan kekuatan 6,9 SR, dan gempa bumi yang memberikan dampak cukup besar terjadi pada 8 Januari 1984 dengan kekuatan 6,7 SR (Damarjati, 2021).

Rencana tindak lanjut dari Pusat Teknologi Reduksi Risiko Bencana (PTRRB) BPPT dari kejadian gempa bumi ini adalah pengumpulan data sekunder yang dikumpulkan dari berbagai sumber dan data primer yang diambil langsung melalui kaji cepat yang dilakukan pada tanggal 16 sampai dengan 21 Februari 2021.

Data primer yang diambil melalui kaji cepat kemudian digunakan untuk membuat pemodelan struktur terhadap bangunanbangunan yang disurvei. Hasilnya dapat digunakan untuk analisis penyebab kerusakan dan rekomendasi untuk pembangunan yang lebih baik ke depannya.

\subsection{Tujuan Penelitian}

Tujuan dari penelitian dan kajian ini adalah untuk mengetahui tingkat perilaku struktur dari bangunan yang mengalami kerusakan pada gempabumi Mamuju 15 Januari 2021. Perilaku saat gempa dapat digunakan untuk perancangan dan pembangunan struktur yang lebih baik di masa mendatang.

\section{BAHAN DAN METODE}

\subsection{Bahan}

Bahan utama yang digunakan dalam penelitian ini adalah data dimensi dan kuat material struktur bangunan-bangunan. Dimana data ini diperoleh dalam kegiatan kaji cepat gempa Mamuju pada tanggal 16-21 Februari 2021.

\subsection{Metode}

Metode penelitian dan pengkajian yang dilakukan adalah:

a. Pengukuran dimensi struktur bangunan (bisa juga diperoleh dari as built drawing, jika ada),

b. Pengukuran kuat tekan beton dengan Hammer Test. Angka yang diperoleh dari hammer test merupakan hasil pengukuran kuat tekan pada struktur utama beton (balok dan kolom).

c. Dimensi dan jumlah tulangan diperoleh dari hasil pengukuran dengan bantuan Profometer. Profometer merupakan alat untuk mengukur dimensi dan jumlah tulangan baja dengan cara memindai struktur beton.

d. Pemodelan bangunan dengan bantuan software analisis struktur bangunan.

e. Pembebanan pada model bangunan yang mengacu pada SNI 1726:2019 tentang Tata Cara Perencanaan Ketahanan Gempa Untuk Struktur Bangunan Gedung dan Nongedung (BSN, 2019a) dan SNI 2847:2019 tentang Persyaratan Beton Struktural untuk Bangunan Gedung dan Penjelasan (BSN, 2019b).

f. Pembebanan gempa yang diberikan untuk setiap model bangunan mengikuti spectral percepatan gempa untuk kota Mamuju (Gambar 3) dengan asumsi jenis "tanah sedang" yang diperoleh dari website puskim.pu.go.id.

Penelitian dan pengkajian dilakukan pada bulan Januari - Maret 2021 baik di Kota Mamuju, Sulawesi Barat, maupun di PTRRB, Puspiptek, Serpong.

\section{HASIL DAN PEMBAHASAN}

\subsection{Spektrum Respon Gempa}

\subsubsection{Spektrum Respon Gempa Terjadi}

Dari rekaman gempa Mamuju 15 Januari 2021 oleh BMKG di Mamuju, percepatan gempa maksimum terjadi di Mamuju adalah 150,8 gals atau $0,15 g\left(g=9,8 \mathrm{~m} /\right.$ detik $\left.^{2}\right)$, dan 
spektrum respon gempa di Mamuju ditunjukkan pada Gambar 1.

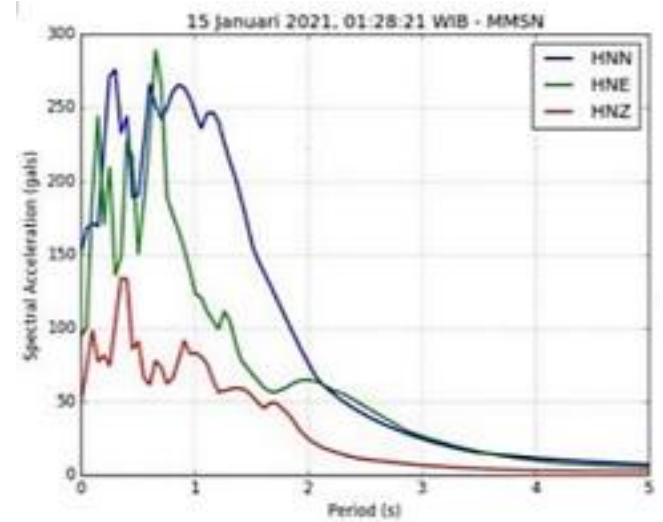

Gambar 1. Spektrum Respon Gempa di Mamuju (Sumber: BMKG, 2021)

Dari gambar tampak bahwa untuk lokasi Mamuju, percepatan respon dapat terjadi sampai dengan sekitar 250 gals (atau 0,25 g) untuk periode getar antara 0,2 - 0,6 detik. Ini berkorelasi dengan bangunan 2 lantai sampai dengan 6 lantai. Oleh karena itu, bangunan dengan jumlah-jumlah lantai tersebut dapat mengalami guncangan yang lebih hebat di kota Mamuju, karena faktor resonansi getaran bangunan dengan getaran gempa.

\subsubsection{Spektrum Respon Gempa Desain}

Spektrum respon gempa desain diperlukan untuk dibandingkan dengan spektrum respon gempa terjadi dan untuk desain bangunan di masa mendatang. Pembebanan untuk model bangunan yang akan dibuat mengacu pada SNI 1726:2019 tentang Tata Cara Perencanaan Ketahanan Gempa Untuk Struktur Bangunan Gedung dan Nongedung (BSN, 2019a). Pembebanan gempa yang diberikan untuk setiap model bangunan mengikuti percepatan spektral gempa desain untuk kota Mamuju (Gambar 2) dengan asumsi jenis "tanah sedang" yang diperoleh dari website puskim.pu.go.id (Kemen PUPR, 2011).

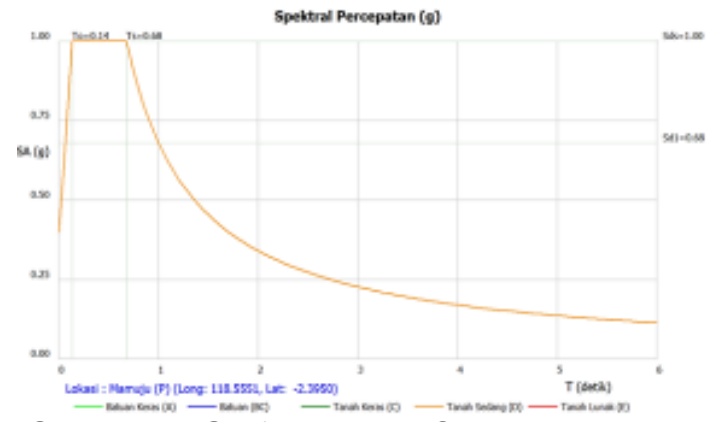

Gambar 2. Grafik Respon Spektrum Desain untuk Daerah Mamuju dengan Jenis "Tanah

Sedang" (SNI 1726:2019 dan website puskim.pu.go.id)

\subsection{Hasil Kajian Lapangan dan Analisis Struktur}

\subsubsection{Bangunan $A$}

Bangunan pertama yang dikaji adalah bangunan kantor di Kota Mamuju. Bangunan ini terbuat dari rangka beton bertulang, dengan sekat berupa dinding bata dan dinding triplek. Dua lantai pertama digunakan untuk ruangan bekerja. Lantai ke-3 digunakan untuk dudukan kerangka atap baja. Bangunan selesai dibangun diperkirakan pada tahun 2010.

Dari hasil survei terlihat kerusakan yang terjadi merupakan kerusakan non-struktur, kerusakan yang dialami bangunan ini diantaranya lepasnya plasteran dinding, plafon yang jatuh, beberapa keramik lepas dan retak, serta terjadi retakan-retakan di dinding bangunan. Dari hasil survei tersebut tidak ditemui kerusakan struktur di bangunan tersebut. Di dalam pengecekan gedung tersebut, tim kaji struktur bangunan melakukan uji Hammer test, profometer, dan pengambilan beberapa gambar kerusakan bangunan yang berguna untuk menambah data pengkajian kerusakan bangunan pada gedung tersebut. Dari hasil bacaan pengukuran kuat tekan beton dengan menggunakan Hammertest didapatkan bahwa kuat tekan pada kolom hanya 16,68 $\mathrm{MPa}$, sedangkan untuk balok jauh lebih kuat yaitu 32,37 MPa.

Dengan memanfaatkan gambar rencana bangunan yang didapatkan dari instansi setempat maka tim kaji struktur bangunan melakukan permodelan gedung menggunakan software. Hal ini dilakukan untuk melakukan simulasi bangunan terhadap kekuatan bangunan ketika terjadi gempa Mamuju 15 Januari 2021 lalu, dan untuk melihat apakah terjadi kerusakan atau tidak pada bangunan tersebut. Setelah dilakukan permodelan dan pendefinisian material dan beban bangunan, maka bangunan dimasukkan percepatan gempa $0,25 \mathrm{~g}$, yaitu percepatan gempa respon yang terjadi saat gempa Mamuju.

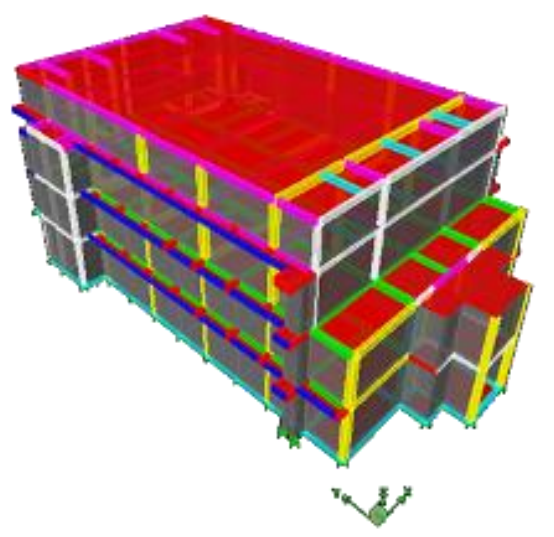

Gambar 3. Model Bangunan A 
Dari hasil permodelan terlihat bahwa kolom di bagian tengah bangunan beberapa di antaranya telah melampaui kapasitas kekuatan kolom akibat percepatan gempa sebesar 0,25 g. Sebagai rekomendasi, dianjurkan untuk menambah perkuatan pada bangunan agar keruntuhan dapat dihindari, jika terjadi gempa lebih besar.

\subsubsection{Bangunan $B$}

Bangunan kedua yang dikaji adalah bangunan kantor juga di Kota Mamuju. Gedung ini menggunakan rangka beton bertulang, dengan sekat berupa dinding bata. Bangunan terdiri dari tiga lantai. Bangunan selesai dibangun diperkirakan pada tahun 2010. Dari hasil survei terlihat kerusakan yang terjadi merupakan kerusakan sebagian struktur kolom di lantai dasar gedung telah melampaui kapasitas kekuatan struktur kolom.

Pemodelan bangunan dibuat berdasarkan denah perencanaan Gedung B Provinsi Sulawesi Barat dan dengan model struktur berdasarkan hasil pengujian (hammer test dan profometer) di lokasi.

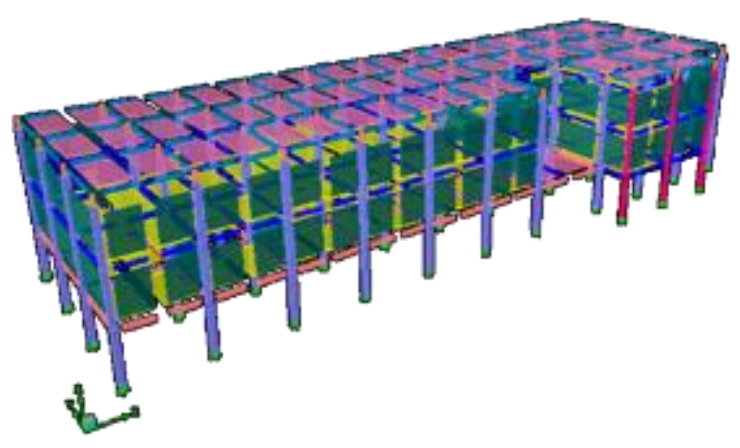

Gambar 4. Model Bangunan B

Setelah Bangunan B dimodelkan, analisis dilanjutkan dengan pengecekan kapasitas struktur. Berdasarkan hasil analisis kapasitas struktur, untuk beban percepatan spectral gempa sebesar 0,1 g, kondisi bangunan masih aman, belum ada kapasitas kolom atau balok yang terlampaui. Analisis dilanjutkan melakukan percobaan untuk beban gempa 0,2 $g$, sudah ada beberapa balok yang kapasitasnya terlampaui. Dan untuk hasil analisis dengan percepatan spectral 0,25 g, mulai ada beberapa kolom yang kapasitasnya terlampaui (kolom berwarna merah pada Gambar 5).

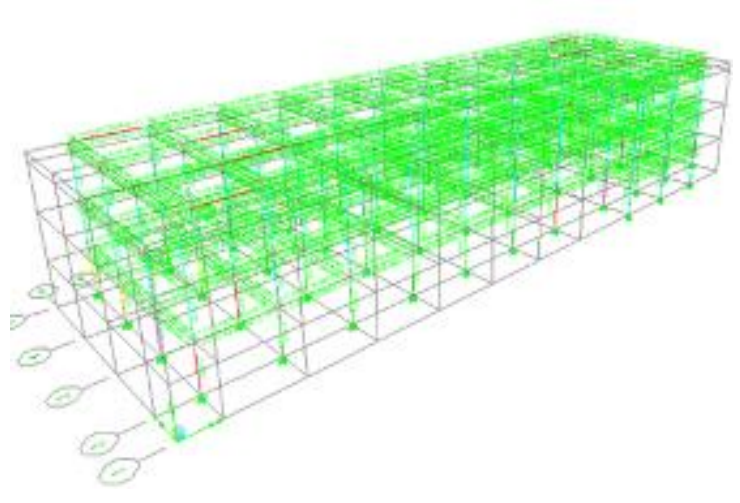

Gambar 5. Hasil Analisis Kapasitas Struktur Bangunan B (Percepatan Gempa 0,25 g)

Berdasarkan beban gempa rencana dari puskim.pu.go.id yang mengacu pada SNI 1726:2019, bangunan direncanakan menerima beban gempa sebesar $1 \mathrm{~g}$ (Gambar 2). Untuk dapat menerima beban sebesar $1 g$ ini maka disarankan untuk menambahkan perkuatan pada bangunan, jika bangunan masih akan digunakan kembali.

\subsubsection{Bangunan $\mathrm{C}$}

Bangunan ketiga yang dikaji adalah bangunan menara di kabupaten Mamuju, berjarak sekitar $27 \mathrm{~km}$ dari Kota Mamuju. Bangunan ini menggunakan rangka beton bertulang, dengan sekat berupa dinding bata. Bangunan terdiri dari enam lantai. Bangunan selesai dibangun diperkirakan pada tahun 2010. Dari hasil survei terlihat kerusakan terjadi hanya pada komponen non-struktur. Pemodelan struktur Bangunan $\mathrm{C}$ ini dibuat dengan bantuan software analisis struktur berdasarkan gambar perencanaan (tahun desain belum diketahui).

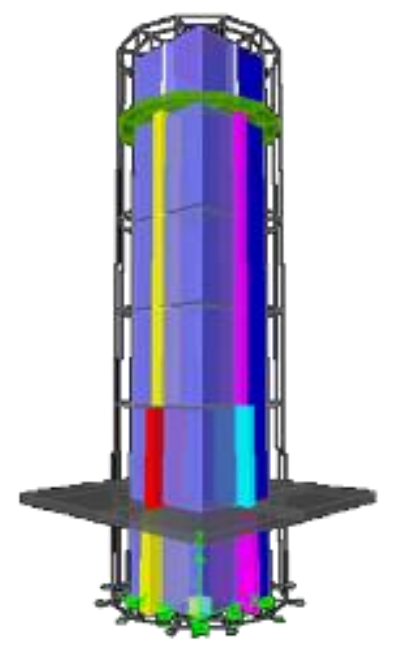

Gambar 6. Model Bangunan C 
Berdasarkan desain SNI 1726:2019 dengan asumsi jenis tanah sedang dan periode getar alami bangunan $\mathrm{T} 1=0,379$ detik (arah $\mathrm{Y}$ ) dan $\mathrm{T} 2=0,245$ detik (arah $\mathrm{X}$ ) maka bangunan direncanakan akan mengalami percepatan sebesar $1 g$ (Gambar 2). Dari hasil analisis kapasitas struktur dengan percepatan $0,2 \mathrm{~g}$, bangunan sudah terlihat mulai terjadi kerusakan pada kolom, ditandai dengan kolom berwarna merah, dan mulai hampir mendekati kerusakan pada kolom di atasnya dengan ditandai warna kuning (Gambar 7). Sehingga untuk menyesuaikan dengan persyaratan pada SNI 1726:2019 diperlukan penyesuaian perkuatan pada bangunan.

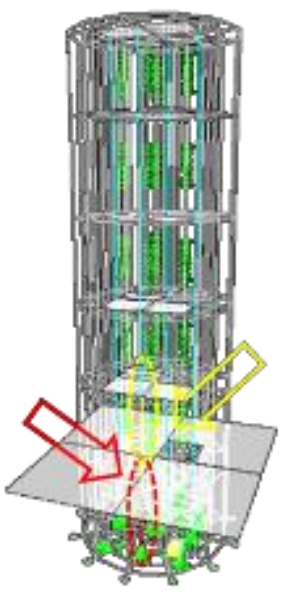

Gambar 7. Hasil Analisis Kapasitas Struktur dengan Percepatan 0,2 $g$ (Mulai Terjadi Kerusakan pada Kolom)

\subsubsection{Bangunan D}

Bangunan keempat yang dikaji adalah bangunan kantor di Kota Mamuju. Bangunan ini menggunakan rangka beton bertulang, dengan sekat berupa dinding bata. Bangunan terdiri dari tiga lantai. Bangunan selesai dibangun diperkirakan pada tahun 2010. Pada saat peninjauan lokasi, bangunan mengalami kerusakan serius baik dari segi struktur maupun arsitektur (non struktural). Hal ini dapat dilihat dengan tampak kolom yang retak hingga memperlihatkan tulangan pada kolom tersebut dan aksesoris gedung yang terlepas dari struktur utama.

Sebagai tindak lanjut dari pelaksanaan survey lapangan, dilaksanakan pemodelan struktur gedung menggunakan software pemodelan, berdasarkan gambar rencana (tahun 2010). Pembebanan pada model gedung dihitung mengikuti ketentuan dalam SNI 1727:2020 dan pemberian percepatan gempa spektral sebesar $0,1 \mathrm{~g}$ sampai dengan $0,25 \mathrm{~g}$.

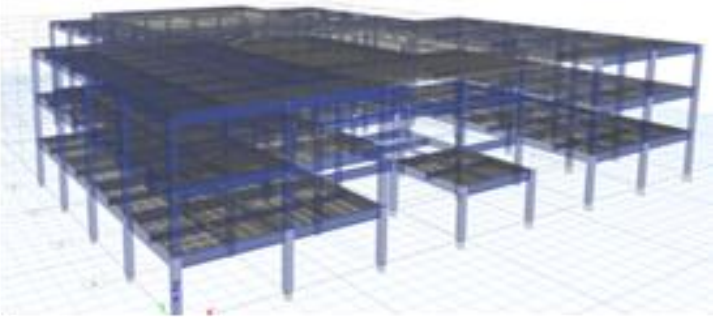

Gambar 8. Model Bangunan D

Berdasarkan hasil analisis struktur bertahap mulai dari percepatan gempa $0,1 \mathrm{~g}$ hingga $0,25 \mathrm{~g}$. Pada percepatan gempa $0,1 \mathrm{~g}$, struktur kolom masih belum terlampuai kapasitasnya. Pada percepatan gempa $0,15 \mathrm{~g}$, sebagian struktur kolom mulai mendekati kapasitas kolomnya. Pada percepatan gempa $0,25 \mathrm{~g}$, hampir sebagian besar struktur kolom di lantai 1 mengalami kerusakan (Gambar 9). Percepatan ini adalah percepatan yang diasumsikan dialami bangunan saat terjadi gempa Januari lalu.

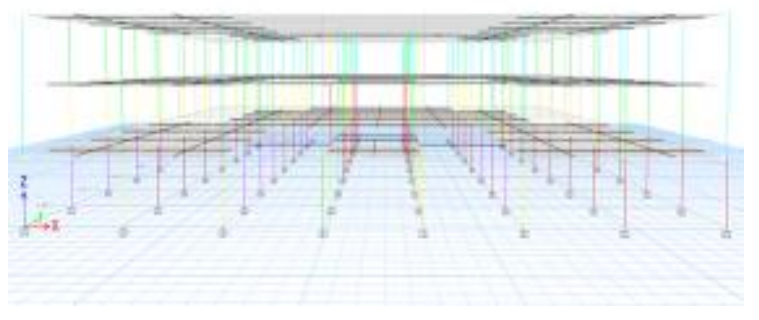

Gambar 9. Hasil Analisis Kapasitas Struktur (Percepatan 0,25 g)

\subsection{Metode Perbaikan / Penyesuaian Perkuatan / Retrofit}

Cara untuk meningkatkan kekuatan struktur bangunan agar dapat menahan beban gempa, diperlukan metode perbaikan pada struktur bangunan. Ada beberapa metode yang dapat digunakan dalam metode perbaikan bangunan, diantaranya menggunakan penambahan bracing baja atau dengan penerapan jacketing pada struktur kolom bangunan.

\subsubsection{Bracing}

Bracing adalah elemen struktur yang diletakan secara menyilang (diagonal) pada struktur portal, dalam hal ini kolom dan balok beton, yang berfungsi untuk menopang/mengaku portal (kolom dan balok beton) dalam menahan beban pada struktur (Nelwan et.al., 2018).

Sistem bracing dapat digunakan untuk menahan gaya vertikal seperti beban gravitasi 
dan gaya horisontal/gaya lateral seperti beban gempa, sehingga dapat mencegah goyangan berlebih pada struktur. Penggunaan bracing juga dimaksudkan agar saat terjadi gempa, gaya lateral yang mengenai struktur tidak hanya ditahan oleh elemen balok dan kolom pada struktur tetapi juga ditahan oleh sistem bracing. Namun, perlu diperhatikan penempatan bracing pada struktur yang berdiri di atas tanah miring karena penempatan bracing yang tidak tepat menyebabkan gaya geser yang terjadi pada kolom pendek lebih besar (Evangelistha et.al., 2019).

\subsubsection{Jacketing}

Jacketing adalah salah satu metode perkuatan atau perbaikan beton dengan cara menyelimuti beton yang telah ada dengan beton tambahan. Konsep dasar metode ini adalah pembesaran dimensi dan penambahan tulangan pada elemen struktur untuk meningkatkan kinerja elemen tersebut. Pembesaran tersebut dilakukan dengan Jacketing. Jacketing dari bahan beton telah terbukti sebagai solusi perkuatan yang efektif untuk meningkatkan kinerja seismik kolom. Teknik perkuatan struktur ini digunakan pada kolom bangunan yang bertujuan untuk memperbesar penampang kolom, maka penampang kolom menjadi besar dari pada sebelumnya sehingga kekuatan geser dan momen beton menjadi meningkat. Keuntungan utama dari metode ini adalah memberikan peningkatan dan pertambahan batas daripada kekuatan dan daktilitas beton (Kaontole et.al., 2015)

\section{KESIMPULAN}

Berikut beberapa kesimpulan yang dapat dirumuskan dari hasil kajian:

- Kajian kerentanan bangunan terhadap gempabumi telah dilakukan pada empat bangunan yang mewakili kantor dan menara di Kota Mamuju.

- Keempat bangunan dimodelkan untuk dapat dipelajari perilaku terhadap percepatan gempabumi, yaitu percepatan spektral saat terjadi gempabumi pada 15 Januari 2021.

- Hasilnya menunjukkan bahwa percepatan di atas mengakibatkan kerusakan pada kolom terutama pada kolom di lantai dasar.

- Jika dilihat pada respon spektrum desain untuk daerah Mamuju dengan jenis "tanah sedang" maka bangunan tipe-tipe tersebut di atas di Kota Mamuju harus mampu menerima percepatan sampai dengan $1 \mathrm{~g}$.

- Dengan demikian untuk pembangunan baru di Kota Mamuju harus memperhatikan percepatan desain di atas dan jika bangunan eksisting akan tetap digunakan, perlu mendapat perkuatan atau retrofit.

- Ada beberapa metode yang dapat digunakan dalam metode perbaikan bangunan, diantaranya menggunakan penambahan bracing baja atau dengan penerapan jacketing pada struktur rangka bangunan.

\section{PERSANTUNAN}

Penulis mengucapkan terima kasih yang sebesar-besarnya kepada pihak-pihak yang telah membantu terselenggaranya kegiatan kajian ini terutama kepada Pemda Kota Mamuju dan Provinsi Sulawesi Barat. Kegiatan ini juga didanai oleh DIPA PTRRB 2021 yang termasuk dalam Program Pengkajian dan Penerapan Teknologi Sistem Peringatan Dini Bencana.

\section{DAFTAR PUSTAKA}

BMKG. 2021. Peta Isoseismal Gempabumi Mamuju - Sulawesi Barat 15 Januari 2021. [terhubung https://www.bmkg.go.id/berita/?p=petaisoseismal-gempabumi-mamuju-sulawesibarat-15-januari-2021\&lang=ID\&s=detil

BNPB. 2021. Sebanyak 81 Orang Meninggal Akibat Gempa M6,2 di Sulawesi Barat. [terhubung berkala]. https://bnpb.go.id/berita/-update-sebanyak81-orang-meninggal-akibat-gempa-m6-2-disulawesi-barat

BSN. 2019a. SNI 1726:2019. Standar Perencanaan Ketahanan Gempa. Untuk Struktur Bangunan Gedung dan Non Gedung. Jakarta. Badan Standarisasi Nasional.

BSN. 2019b. SNI 2847:2019. Persyaratan beton struktural untuk bangunan gedung dan penjelasan. Jakarta. Badan Standarisasi Nasional.

BSN. 2020. SNI 1727:2020. Beban Desain Minimum dan Kriteria Terkait untuk Bangunan Gedung dan Struktur Lain. Jakarta. Badan Standarisasi Nasional.

Damarjati, Danu. 2021. Sejarah Gempa dan Tsunami Majene 1969: Renggut 600 Korban Jiwa. https://news.detik.com/berita/d5335498/sejarah-gempa-dan-tsunamimajene-1969-renggut-600-korban-jiwa/2

Evangelistha, F. dan Rienanda. 2019. Pengaruh Bracing Pada Bangunan Bertingkat Rangka Baja yang Berdiri di Atas Tanah Miring 
Terhadap Gempa. Jurnal Teknik Sipil Statik, $7(6)$

Kaontole, J. T., M. D. J. Sumajouw, dan R. S. Windah. 2015. Evaluasi Kapasitas Kolom Beton Bertulang yang Diperkuat dengan Metode Concrete Jacketing. Manado: Universitas Sam Ratulangi. Jurnal Teknik Sipil Statik, 3(3)

Kemen PUPR. 2011. Desain Spektra Indonesia. http://puskim.pu.go.id/Aplikasi/desain_spekt ra_indonesia_2011/

Kemen PUPR. 2017. Peta Sumber dan Bahaya Gempa Indonesia tahun 2017. Pusat Penelitian dan Pengembangan Perumahan dan Permukiman, Badan Penelitian dan Pengembangan. ISBN: 978-602-5489-01-3. 400p.

Nelwan, I. T., S. E. Wallah, dan S. O. Dapas. 2018. Respon Dinamis Bangunan Bertingkat Banyak dengan Soft First Story dan Penggunaan Braced Frames Element Terhadap Beban Gempa. Jurnal Teknik Sipil Statik, 6(3) 